CLINICAL STUDY

\title{
Increased plasminogen activator inhibitor-1, decreased tissue factor pathway inhibitor, and unchanged thrombin-activatable fibrinolysis inhibitor levels in patients with primary hyperparathyroidism
}

\author{
Cihangir Erem, Mustafa Kocak, İran Nuhoglu, Mustafa Yilmaz ${ }^{1}$ and Ozge Ucuncu \\ Division of Endocrinology and Metabolism, Department of Internal Medicine, Faculty of Medicine, Karadeniz Technical University, 61080 Trabzon, Turkey \\ and ${ }^{1}$ Division of Hematology, Department of Internal Medicine, Faculty of Medicine, Karadeniz Technical University, 61080 Trabzon, Turkey \\ (Correspondence should be addressed to C Erem; Email: cihangirerem@meds.ktu.edu.tr)
}

\begin{abstract}
Background and objectives: Primary hyperparathyroidism (PHPT) is associated with increased cardiovascular mortality and morbidity. Little is known about hemostatic features of patients with PHPT. To our knowledge, plasma tissue factor pathway inhibitor (TFPI) and thrombin-activatable fibrinolysis inhibitor (TAFI) levels in these patints have not been investigated. Therefore, the main purpose of this study was to evaluate the markers of endogenous coagulation/fibrinolysis, including TFPI and TAFI, and to investigate the relationships between serum calcium and PTH and these hemostatic parameters in patients with PHPT.

Design and methods: Twenty-four patients with PHPT and 20 age-, sex-, and-weight-matched healthy controls were included in the study. Tissue plasminogen activator (t-PA), tissue plasminogen activator inhibitor-1 (PAI-1), TFPI, and TAFI were measured. The relationships between serum calcium, phosphorus, and PTH and these hemostatic parameters were examinated.

Results: Compared with the control subjects, t-PA, PAI-1, and PAI-1/t-PA ratios were significantly increased in patients with PHPT $(P<0.0001)$, whereas TFPI levels were significantly decreased $(P<0.0001)$. Plasma TAFI Ag levels did not significantly change in patients with PHPT compared with the controls. In patients with PHPT, serum phosphorus was negatively correlated with plasma PAI-1 $\mathrm{Ag}$ levels and PAI-1/t-PA ratio $(r:-0.453, P<0.05 ; r$ : $-0.580, P<0.01$ respectively). There was a positive correlation between $\mathrm{Cl} / \mathrm{P}$ ratio and plasma PAI-1 levels and PAI-1/t-PA ratio $(r$ : 0.434 , $P<0.05 ; r: 0.528, P<0.05$ respectively). iPTH was positively correlated with plasma PAI-1/t-PA ratio ( $r: 0.429, P<0.05)$.

Interpretation and conclusions: In conclusion, we found some important differences in the hemostatic parameters between the patients with PHPT and healthy controls. Increased PAI-1, PAI-1/t-PA ratios and decreased TFPI levels in these patients represent a potential hypercoagulable and hypofibrinolytic state, which might augment the risk for atherosclerotic and atherothrombotic complications. This condition may contribute to the excess mortality due to cardiovascular disease seen in patients with PHPT.
\end{abstract}

European Journal of Endocrinology 160 863-868

\section{Introduction}

Primary hyperparathyroidism (PHPT) has been associated with increased cardiovascular mortality and morbidity rate (1-3). The causes of increased cardiovascular risk associated with PHPT are systemic arterial hypertension (4), left ventricular hypertrophy (5), valvular and myocardial calcification (6), dysfunction in vascular reactivity $(7,8)$, vascular structural changes (9), arrhythmias (10), impaired glucose metabolism $(11,12)$, dyslipidemia (13), and increased body mass index (14). Very recently, changes in coagulation and fibrinolytic systems have been reported in patients PHPT, which might also have a role in the pathogenesis of cardiovascular disease (CVD) in this disease $(12,15)$.

High serum calcium and PTH levels may have harmful effects on the cardiovascular system and are known to be correlated with the risk of premature cardiovascular death $(16,17)$. Serum calcium levels have been demonstrated to be an independent predictor of mortality even within the reference ranges (18). In addition, Kamycheva et al. reported that serum PTH predicts coronary heart disease in subjects with calcium 
levels within the reference range (17). However, the exact role of PTH and/or calcium in the development of CVD is still controversial $(19,20)$.

High levels of serum calcium and circulating PTH increase plasma clotting factors and impair fibrinolytic capacity (decreased fibrinolytic activity) (5, 21, 22). Increased platelet count and coagulation factors, including factors VII (FVII) and X (FX), D-dimer, and plasminogen activator inhibitor-1 (PAI-1) are reported in the patients with PHPT $(12,15)$. It has been suggested that because of these alterations in the coagulation and fibrinolysis, patients with PHPT have a tendency toward hypercoagulability $(12,15)$.

The thrombin-activatable fibrinolysis inhibitor (TAFI), an enzyme that may act as a link between coagulation and fibrinolysis, inhibits fibrinolysis by removing carboxyterminal residues from partially degraded fibrin, thus decreasing plasminogen binding on the surface of fibrin $(23,24)$. Increased TAFI levels have been associated with several thrombotic conditions like venous thromboembolism $(25,26)$ and ischemic stroke $(27,28)$. Tissue factor pathway inhibitor (TFPI) is secreted by the endothelium and stored in platelets (29). TFPI binds directly and inhibits the earliest steps in extrinsic pathway activation by binding factor Xa (which involved in the activation of prothrombin to thrombin) and tissue factor (TF)/factor VIIa complexes in an inactive quaternary complex (30). Low plasma TFPI levels have been reported in patients with ischemic stroke (31), thrombotic thrombocytopenic purpura (32), and in women taking combined oral contraceptives (33).

Although some studies indicate that coagulation and fibrinolytic system are disturbed in the patients with PHPT, the levels of plasma TAFI antigen and TFPI have not been investigated in patients with PHPT. Therefore, in a case-control study, we determined the profile of coagulation and fibrinolytic parameters including TAFI and TFPI in patients with symptomatic PHPT. We also investigated the relationships serum calcium and PTH levels and hemostatic parameters in these patients. A hypercoagulable state might increase the risk for thromboembolic complications and predispose to an increased prevalence of vascular disease.

\section{Design and methods}

\section{Patients and study design}

The study was performed at Karadeniz Technical University Medical Faculty, Department of Internal Medicine. We evaluated 24 untreated patients with classic symptomatic PHPT ( 20 women and 4 men; mean age, $51.3 \pm 12.1$ years). Those patients admitted from other hospitals in Trabzon city and surrounding cities to our clinic to investigate etiology of hypercalcemia and/or those directly admitted to our clinic with symptoms of PHPT were included in the study.
The diagnosis of PHPT was based on clinical assessment and biochemical findings with a combination of hypercalcemia (serum calcium $>10.5 \mathrm{mg} / \mathrm{dl}$ ) and elevated intact PTH levels (iPTH $>69 \mathrm{pg} / \mathrm{ml}$ ) supported by other laboratory findings, such as hypophosphatemia (serum phosphorus $<2.7 \mathrm{mg} / \mathrm{dl}$ ), increased alkaline phosphatase, increased urinary calcium and phosphate excretions (UCE and UPE respectively), and decreased tubular reabsorption of phosphate. Etiology of PHPT was solitary parathyroid adenomas in 20 cases and primary hyperplasia of the parathyroids in four cases.

Patients neither received any medical treatments (e.g. estrogen therapy) nor had any known diseases (e.g. diabetes mellitus, thyroid dysfunction, coronary heart disease, collagen disease, liver cirrhosis, atrial fibrillation, or renal disease), which might affect blood coagulation or fibrinolysis at the time of the study, were not included to the study. At diagnosis, the patients with risk factors for coagulation and thromboembolism including known cancer, pregnancy, known thrombophilia, recent childbirth, and use of oral contraceptives were excluded from patient group. Twenty healthy ageand sex-matched subjects ( 17 women and 3 men, mean age $48.8 \pm 10.4$ years) were used as controls. Their biochemical values were within normal ranges. None of the controls were taking any drugs affecting the levels of serum cortisol and hemostatic parameters. All participants including patients and control subjects were non-smokers, and there was neither minor illness (e.g. viral infections) nor family history of clotting disorders in either the patients or the control subjects.

\section{Laboratory analysis}

Blood was collected in the morning between 0800 and $0900 \mathrm{~h}$ after an overnight fast to avoid the differences of diurnal variation, especially for hemostatic parameters. The concentration of intact PTH in the plasma was determined using commercial two-side chemiluminescent enzyme-labeled immunometric assay (Immulite 2000 PTH, DPC, Los Angeles, CA, 90045-6900, USA). Intra and interassay coefficients of variation $(\mathrm{cv})$ were $4.3 \%$ (at $258 \mathrm{pg} / \mathrm{ml}$ ) and $8.8 \%$ (at $387 \mathrm{pg} / \mathrm{ml}$ ) respectively. Detection limit is $3-2500 \mathrm{pg} / \mathrm{ml}(0.3-263 \mathrm{pmol} / \mathrm{l})$. Normal ranges of biochemical parameters were $8.5-10.5 \mathrm{mg} / \mathrm{dl}$ for serum calcium, $2.7-4.5 \mathrm{mg} / \mathrm{dl}$ for serum phosphate, $0.5-1.2 \mathrm{mg} / \mathrm{dl}(44.2-106.1 \mu \mathrm{mol} / \mathrm{l})$ for serum creatinine, and $12-69 \mathrm{pg} / \mathrm{ml}$ for plasma iPTH concentration. Routine analyses were carried out by autoanalyzer (Technicon Axon, Tarrytown, USA).

For coagulation and fibrinolysis, a venous blood sample $(9$ vol $)$ was collected into vacutainer tubes (Becton Dickinson, Mountain View, CA, USA) containing $0.129 \mathrm{~mol} / \mathrm{l}$ trisodium citrate $(1 \mathrm{vol})$. Platelet-poor plasma was obtained by centrifugation at $3500 \boldsymbol{g}$ at $10{ }^{\circ} \mathrm{C}$ for $20 \mathrm{~min}$. Aliquots of plasma were transferred into plastic tubes without delay and frozen at $-80{ }^{\circ} \mathrm{C}$ 
Table 1 Clinical and biological parameters of controls and patients with primary hyperparathyroidism.

\begin{tabular}{|c|c|c|c|}
\hline & Controls & PHPT & $P$ \\
\hline Number of subjects & 20 & 24 & _ \\
\hline Age (years) & $48.8 \pm 10.4$ & $51.3 \pm 12.1$ & NS \\
\hline BMI $\left(\mathrm{kg} / \mathrm{m}^{2}\right)$ & $27.9 \pm 5.6$ & $28.4 \pm 4.3$ & NS \\
\hline $\mathrm{SBP}(\mathrm{mmHg})$ & $123 \pm 8.9$ & $121.7 \pm 11.7$ & NS \\
\hline $\mathrm{DBP}(\mathrm{mmHg})$ & $77.9 \pm 7.0$ & $76.3 \pm 7.7$ & NS \\
\hline Calcium (mg/dl) (N: 8.5-10.5) & $9.6 \pm 0.4$ & $12.5 \pm 1.7$ & $<0.0001$ \\
\hline Phosphorus (mg/dl) (N: 2.7-4.5) & $3.9 \pm 0.5$ & $2.7 \pm 0.6$ & $<0.0001$ \\
\hline $\mathrm{Cl} / \mathrm{P}$ ratio & $26.9 \pm 3.6$ & $42 . \overline{3} \pm 14.7$ & $<0.0001$ \\
\hline UCE $(\mathrm{mg} / 24 \mathrm{~h})(\mathrm{N}: 50-300 \mathrm{mg} / \mathrm{d})$ & - & $524.3 \pm 185.3$ & - \\
\hline UPE $(\mathrm{mg} / 24 \mathrm{~h})(\mathrm{N}: 400-1300 \mathrm{mg} / \mathrm{d})$ & - & $858.2 \pm 288.3$ & - \\
\hline TRP (\%) (N: $80-97 \%)$ & _ & $77.9 \pm 8.6$ & _ \\
\hline ¡PTH (pg/ml) (N: 12-69) & $36.0 \pm 10.1$ & $501.8 \pm 487.4$ & $<0.0001$ \\
\hline t-PA Ag (ng/ml) & $13.5+2.6$ & $20.2+5.7$ & $<0.0001$ \\
\hline PAl-1 Ag (ng/ml) & $29.4 \pm 7.9$ & $99.1 \pm 53.1$ & $<0.0001$ \\
\hline PAI-1/t-PA ratio & $2.3+0.8$ & $4.9+2.6$ & $<0.0001$ \\
\hline TFPI $\mathrm{Ag}(\mathrm{ng} / \mathrm{ml})$ & $88.7 \pm 15.6$ & $70.3 \pm 10.9$ & $<0.0001$ \\
\hline TAFI Ag (\%) & $148.6 \pm 24.3$ & $141 \pm 7.0$ & NS \\
\hline
\end{tabular}

NS, non significant $(P>0.05)$; BMI, body mass index; SBP, systolic blood pressure; DBP, diastolic blood pressure; UCE, urinary calcium excretion; UPE, urinary phosphate excretion; TRP, tubular reabsorption of phosphate; iPTH, intact parathyroid hormone; t-PA, tissue plasminogen activator; PAl-1, plasminogen activator inhibitor-1; TFPI, tissue factor pathway inhibitor and TAFI, thrombin-activatable fibrinolysis inhibitor.

until assays for determination of t-PA and PAI-1. T-PA, PAI-1, TAFI Ag, and TFPI assays were performed by ELISA using commercial kits of American Diagnostica. According to our hematology laboratory, normal ranges are $1-20 \mathrm{ng} / \mathrm{ml}$ for t-PA Ag, $20-44 \mathrm{ng} / \mathrm{ml}$ for PAI-1 Ag, 40-250\% for TAFI, and 75-120 ng/ml for TFPI Ag.

\section{Statistical analysis}

Statistical analyses were performed by Student's $t$-test for normal distribution data and Mann-Whitney U-test for not normal distribution data. In patient group, correlations among biochemical parameters and iPTH and coagulation were carried out using Pearson (normal distribution data) and Spearman (not normal distribution data) correlation analysis. Results are cited as mean \pm s.D. $P<0.05$ was accepted as statistically significant.

\section{Results}

Table 1 summarizes the clinical characteristics and laboratory parameters in patients with PHPT and control subjects. As expected, the mean serum calcium, chloride-to-phosphorus ratio ( $\mathrm{Cl} / \mathrm{P}$ ratio), and $\mathrm{iPTH}$ levels were significantly higher in the patient group than those in controls, whereas serum phosphorus levels were significantly decreased.

Compared with the control subjects, t-PA, PAI-1, and $\mathrm{PAI}-1 / \mathrm{t}-\mathrm{PA}$ ratios were significantly increased in patients with PHPT $(P<0.0001)$, whereas TFPI levels were significantly decreased $(P<0.0001)$. Plasma TAFI Ag levels did not significantly change in patients with PHPT compared with the controls. The other coagulation/fibrinolysis parameters in patients with PHPT were not different from the controls. Moreover, the levels of parameters of patients with parathyroid hyperplasia were not found to be different from those of patients with solitary parathyroid adenoma.

In patients with PHPT, serum phosphorus was negatively correlated with plasma PAI-1 Ag levels and PAI-1/t-PA ratio $(r:-0.453, P<0.05 ; r:-0.580$, $P<0.01$ respectively; Figs 1 and 2). There was a positive correlation between $\mathrm{Cl} / \mathrm{P}$ ratio and plasma $\mathrm{PAI}-1$ levels and PAI-1/t-PA ratio ( $r$ : $0.434, P<0.05 ; r$ : 0.528 , $P<0.05$ respectively; Figs 3 and 4 ). iPTH was positively correlated with plasma PAI-1/t-PA ratio ( $r$ : 0.429 , $P<0.05$; Fig. 5). We did not find any significant correlation between iPTH and serum calcium and the hemostatic parameters that we measured.

\section{Discussion}

The role of PHPT in heart disease is still controversial $(3,6)$. However, patients with PHPT seem to have an increase in morbidity and mortality. This condition is

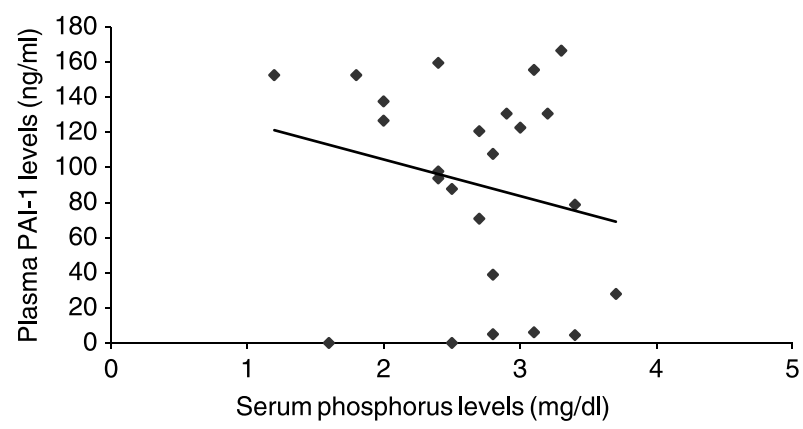

Figure 1 Correlation between serum phosphorus levels and PAI-1 Ag levels in patients with PHPT $(r:-0.453, P<0.05)$. 


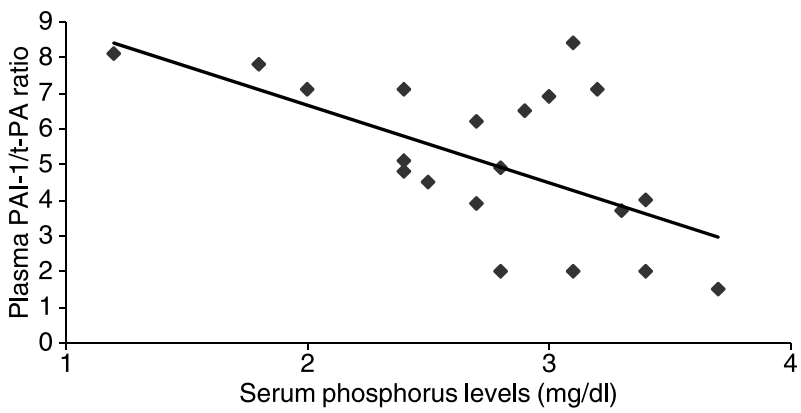

Figure 2 Correlation between serum phosphorus levels and PAI$1 / \mathrm{t}-\mathrm{PA}$ ratio in patients with PHPT $(r:-0.580, P<0.01)$.

mainly due to cardiovascular death $(2,3)$. PHPT is associated with hypertension, coronary heart disease, and other CVDs $(7,15,17)$.

There are only two studies to evaluate the hemostatic parameters in patients with PHPT $(12,15)$. In our previous study, we reported that increased platelet count, FVII and FX activities, and D-dimer levels in patients with PHPT represent a potential hypercoagulable state, which might augment the risk for atherosclerotic and atherothrombotic complications (15).

T-PA produced by vascular endothelial cells converts plasminogen to plasmin, which degrades fibrin (34). Epidemiological studies have shown that plasma t-PA levels positively predict future coronary events in the patients with ischemic heart disease and in a healthy male population $(35,36)$. On the other hand, endothelial cells also produce PAI-1 (37). It has been shown that PAI-1, the main inhibitor of the fibrinolytic system, and fibrinogen are both associated with coronary heart disease (38). At present, there are no compelling epidemiological studies that define PAI- 1 as a clear risk factor for arterial thrombotic complications (39). However, the association of hemostatic variables with CVD risk factors and prevalent CVD was investigated in the prospective cohort PRIME study of myocardial infarction in men aged $50-59$ years $(40,41)$. In this study, it was reported that the statistically significant $(P<0.001)$ CVD odds ratio for one standard deviation in PAI-1 was 1.38 (CI 1.27-1.49) (40, 41).

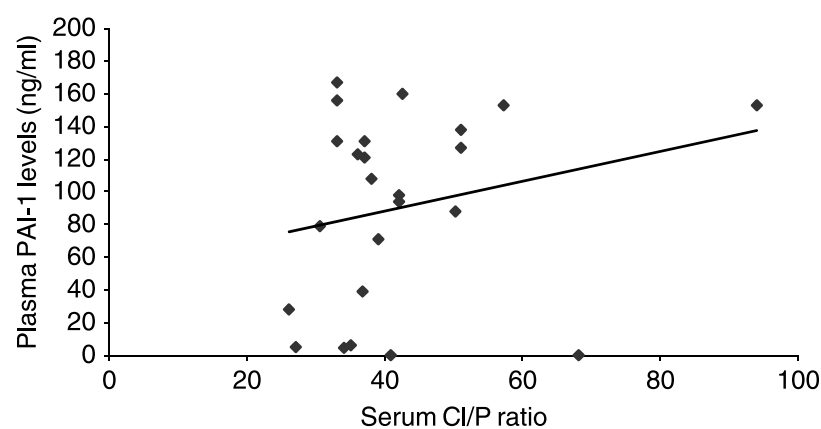

Figure 3 Correlation between $\mathrm{Cl} / \mathrm{P}$ ratio and $\mathrm{PAl}-1 \mathrm{Ag}$ levels in patients with PHPT ( $r: 0.434, P<0.05)$.

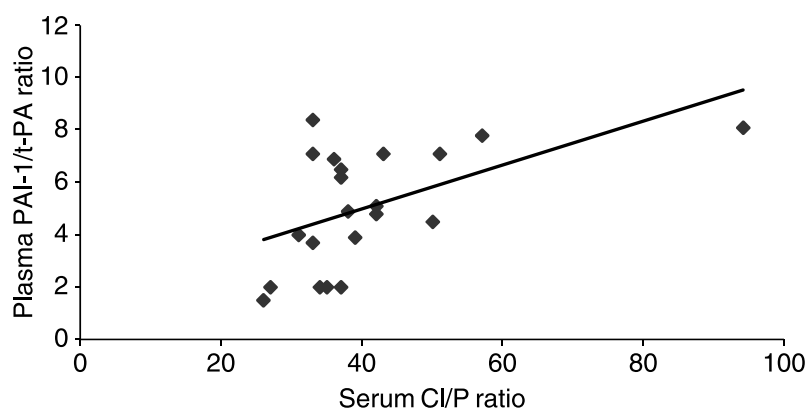

Figure 4 Correlation between $\mathrm{Cl} / \mathrm{P}$ and $\mathrm{PAl}-1 / \mathrm{t}-\mathrm{PA}$ ratios in patients with PHPT $(r: 0.528, P<0.05)$

On the basis of intensive investigations, the t-PA/PAI-1 system has been viewed as a potential control point of fibrinolysis. Hypofibrinolysis is characterized by increased PAI activity and decreased t-PA (40). Chertok-Shacham et al. reported that elevated PAI-1 levels in symptomatic patients with PHPT may imply that hypercoagulability may be involved in the pathogenesis of CVD in these patients (12). In the present study, we found a significant increase in PAI-1 levels in patients with PHPT. This result is consistent with the results by Chertok-Shacham et al. (12). Moreover, in the present study, PAI-1 was negatively correlated with serum phosphorus levels and positively correlated with $\mathrm{Cl} / \mathrm{P}$ ratio. In addition, there was a positive correlation between iPTH and PAI-1/t-PA ratios. In our study, increased PAI-1 levels in patients with PHPT may be the tendency to thromboembolic events by lowering fibrinolytic activity. The mechanism of changes in plasma t-PA and PAI-1 remains unknown. However, it seems likely that iPTH may influence the synthesis and metabolism of t-PA and especially PAI-1 in the vascular endothelial cells. The increase in t-PA may be also a protective mechanism and/or compensatory response versus hypercoagulable state seen in PHPT. Our data also indicate that the balance between t-PA and PAI-1 is disturbed in favour of PAI-1 in patients with PHPT.

TFPI, a potent anticoagulant protein, inhibits the activity of the TF-factor VIIa catalytic complex that is involved in activation of IX to IXa and also directly

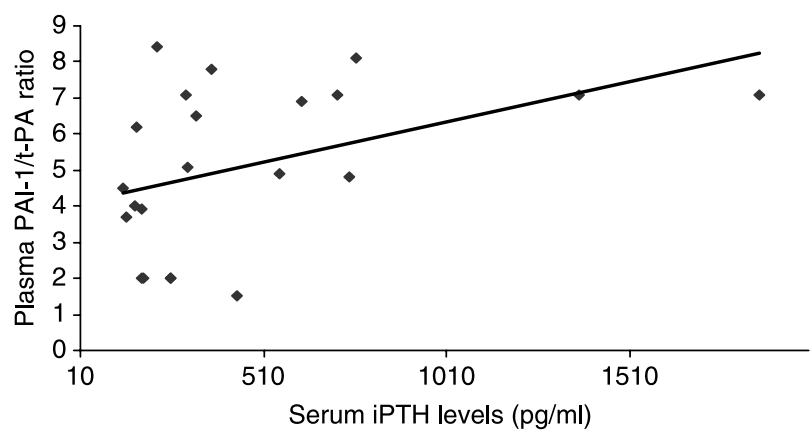

Figure 5 Correlation between iPTH and PAl-1/t-PA ratios in patients with PHPT ( $r: 0.429, P<0.05)$. 
inhibits FXa that activates blood coagulation $(29,42)$. Both endothelial cells and platelets produce TFPI (42). Low TFPI is a risk factor for a first venous thrombosis, recurrent venous thromboembolism, and stroke $(31,43,44)$. To our knowledge, plasma TFPI Ag levels have not been investigated in patients with PHPT. In the present study, we found a significant decrease in TFPI levels in patients with PHPT. Decreased TFPI levels in patients with PHPT may be the tendency to thrombosis and coagulation in these patients. However, we did not find an association between iPTH and serum calcium levels and TFPI levels in the correlation analysis.

TAFI, also known as procarboxypeptidase $\mathrm{B}$, is a plasma zymogen that potently inhibits fibrinolysis $(45,46)$. It protects the fibrin clots from breakdown by removing $\mathrm{C}$-terminal lysine residues from partially degraded fibrin, which are necessary for t-PA-mediated plasmin regeneration (46). Increased activation of TAFI might exacerbate a prothrombotic disposition. Increased plasma TAFI Ag levels were associated with a mild risk for venous thrombosis (25). One study reported that patients with a recent myocardial infarction presented lower TAFI Ag values and that increased TAFI levels were actually protective against myocardial infarction (47). On the other hand, high TAFI levels were reported to be associated with an increased risk of first ischemic stroke (27). To our knowledge, this is the first study to evaluate TAFI Ag levels in patients with PHPT. In the present study, TAFI Ag levels did not change in our patients with PHPT.

In conclusion, we found some important differences in the hemostatic parameters between the patients with PHPT and healthy controls. Increased t-PA and PAI-1 and decreased TFPI levels in these patients represent a potential hypercoagulable and hypofibrinolytic state, which might augment the risk for atherosclerotic and atherothrombotic complications. This condition may contribute to the excess mortality due to CVD seen in patients with PHPT. However, our study comprised a small number of patients with PHPT. A larger number of patients should be included in a prospective study to explain the association between PHPT and TAFI.

\section{Declaration of interest}

The authors declare that there is no conflict of interest that would prejudice the impartiality of this scientific work.

\section{Funding}

This research did not receive any specific grant from any funding agency in the public, commercial, or not-for-profit sector.

\section{Acknowledgements}

We are grateful to Yıldıray Karayavuz from Haematology Laboratory for help in laboratory analyses.

\section{References}

1 Andersson P, Rydberg E \& Willenheimer R. Primary hyperparathyroidism and heart disease-a review. European Heart Journal $2004251776-1787$.

2 Hedback G \& Oden A. Increased risk of death from primary hyperparathyroidism-an update. European Journal of Clinical Investigation 199828 271-276.

3 Kiernan TJ, O'Flynn AM, McDermott JH \& Kearney P. Primary hyperparathyroidism and the cardiovascular system. International Journal of Cardiology 2006113 E89-E92.

4 Rapado A. Arterial hypertension and primary hyperparathyroidism, incidence and follow-up after parathyroidectomy. American Journal of Nephrology 19866 (Suppl 1) 49-50.

5 Piovesan A, Molineri N, Casasso F, Emmolo I, Ugliengo G, Cesario F \& Borretta G. Left ventricular hypertrophy in primary hyperparathyroidism. Effects of successful parathyroidectomy. Clinical Endocrinology 199950 321-328.

6 Stefenelli T, Abela C, Frank H, Koller-Strametz J, Globits S, BerglerKlein J \& Niederle B. Cardiac abnormalities in patients with primary hyperparathyroidism: implications for follow-up. Journal of Clinical Endocrinology and Metabolism 1997 82 106-112.

7 Baykan M, Erem C, Erdogan T, Hacihasanoglu A, Gedikli O, Kiris A, Kucukosmanoglu M, Ersoz HO \& Celik S. Impairment of flow mediated vasodilatation of brachial artery in patients with primary hyperparathyroidism. International Journal of Cardiovascular Imaging 200723 323-328.

8 Kosch M, Hausberg M, Vormbrock K, Kisters K, Rahn KH \& Barenbrock M. Studies on flow-mediated vasodilation and intimamedia thickness of the brachial artery in patients with primary hyperparathyroidism. American Journal of Hypertension 200013 759-764.

9 Chadwick DR, Harrison BJ, Chan P, Chong L \& Peachell P. Vasoactive and proliferative effects of parathyroid hormone and parathyroid hormone-related peptide on human vascular smooth muscle. British Journal of Surgery 200087 1529-1533.

10 Lind L \& Ljunghall S. Serum calcium and the ECG in patients with primary hyperparathyroidism. Journal of Electrocardiology 199427 99-103.

11 Procopio M, Magro G, Cesario F, Piovesan A, Pia A, Molineri N \& Borretta G. The oral glucose tolerance test reveals a high frequency of both impaired glucose tolerance and undiagnosed type 2 diabetes mellitus in primary hyperparathyroidism. Diabetic Medicine 200219 958-961.

12 Chertok-Shacham E, Ishay A, Lavi I \& Luboshitzky R. Biomarkers of hypercoagulability and inflammation in primary hyperparathyroidism. Medical Science Monitor 200814 CR628-CR632.

13 Hagstrom E, Lundgren E, Lithell H, Berglund L, Ljunghall S, Hellman P \& Rastad J. Normalized dyslipidaemia after parathyroidectomy in mild primary hyperparathyroidism: populationbased study over 5 years. Clinical Endocrinology 200256 253-260.

14 Grey AB, Evans MC, Stapleton JP \& Reid IR. Body weight and bone mineral density in postmenopausal women with primary hyperparathyroidism. Annals of Internal Medicine $1994 \mathbf{1 2 1}$ 745-749.

15 Erem C, Kocak M, Hacihasanoglu A, Yilmaz M, Saglam F \& Ersoz HO. Blood coagulation, fibrinolysis and lipid profile in patients with primary hyperparathyroidism: increased plasma factor VII and X activities and D-dimer levels. Experimental and Clinical Endocrinology and Diabetes 2008116 619-624.

16 Wermers RA, Khosla S, Atkinson EJ, Grant CS, Hodgson SF, O'Fallon WM \& Melton LJ. Survival after the diagnosis of hyperparathyroidism: a population-based study. American Journal of Medicine $1998 \mathbf{1 0 4} 115-122$.

17 Kamycheva E, Sundsfjord J \& Jorde R. Serum parathyroid hormone levels predict coronary heart disease: the Tromso study. European Journal of Cardiovascular Prevention and Rehabilitation 200411 69-74. 
18 Garcia de la Torre N, Wass JA \& Turner HE. Parathyroid adenomas and cardiovascular risk. Endocrine Related Cancer 200310 309-322.

19 Fallo F, Camporese G, Capitelli E, Andreozzi GM, Mantero F \& Lumachi F. Ultrasound evaluation of carotide artery in primary hyperparathyroidism. Journal of Clinical Endocrinology and Metabolism 200388 2096-2099.

20 Lumachi E, Ermani M, Luisetto G, Nardi A, Basso SMM, Camozzi V \& Favia G. Relationship between serum parathyroid hormone, serum calcium and arterial blood pressure in patients with primary hyperparathyroidism: results of a multivariate analysis. European Journal of Endocrinology 2002146 643-647.

21 Hueper W. Metastatic calcifications in the organs of the dog after injections of parathyroid extract. Archives of Pathology 19273 $14-25$.

22 Hilgard P. Experimental hypercalcaemia and whole blood clotting. Journal of Clinical Pathology 197326 616-619.

23 Rooth E, Wallen H, Antovic A, von Arbin M, Kaponides G, Wahlgren N, Blombäck M \& Antovic J. Thrombin activatable fibrinolysis inhibitor and its relationship to fibrinolysis and inflammation during the acute and convalescent phase of ischemic stroke. Blood Coagulation and Fibrinolysis 200718 365-370.

24 Redlitz A, Tan AK, Eaton DL \& Plow EF. Plasma carboxypeptidases as regulators of the plasminogen system. Journal of Clinical Investigation 199596 2534-2538.

25 van Tilburg NH, Rosendaal FR \& Bertina RM. Thrombin activatable fibrinolysis inhibitor and the risk for deep vein thrombosis. Blood 200095 2855-2859.

26 Eichinger S, Schönauer V, Weltermann A, Minar E, Bialonczyk C, Hirschl M, Schneider B, Quehenberger P \& Kyrle PA. Thrombinactivatable fibrinolysis inhibitor and the risk for recurrent venous thromboembolism. Blood 2004103 3773-3776.

27 Leebeek FW, Goor MP, Guimaraes AH, Brouwers GJ, Maat MP, Dippel DW \& Rijken DC. High functional levels of thrombinactivatable fibrinolysis inhibitor are associated with an increased risk of first ischemic stroke. Journal of Thrombosis and Haemostasis $200532211-2218$.

28 Montaner J, Ribó M, Monasterio J, Molina CA \& Alvarez-Sabín J. Thrombin-activable fibrinolysis inhibitor levels in the acute phase of ischemic stroke. Stroke 200334 1038-1040.

29 Ravindranath TM, Goto M, Iqbal O, Florian-Kujawski M, Hoppensteadt D, Hammadeh R, Sayeed MM \& Fareed J. Plasma thrombin activatable fibrinolysis inhibitor and tissue factor pathway inhibitor changes following sepsis. Clinical and Applied Thrombosis/Hemostasis 200713 362-368.

30 Broze GJ Jr. The role of tissue factor pathway inhibitor in a revised coagulation cascade. Seminars in Hematology 199229 159-169.

31 Abumiya T, Yamaguchi T, Terasaki T, Kokawa T, Kario K \& Kato H. Decreased plasma tissue factor pathway inhibitor activity in ischemic stroke patients. Thrombosis and Haemostasis $1995 \mathbf{7 4}$ 1050-1054.

32 Kobayashi M, Wada H, Wakita Y, Shimura M, Nakase T, Hiyoyama K, Nagaya S, Minami N, Nakano T \& Shiku H. Decreased plasma tissue factor pathway inhibitor levels in patients with thrombotic thrombocytopenic purpura. Thrombosis and Haemostasis 199573 10-14.

33 Harris GM, Stendt CL, Vollenhoven BJ, Gan TE \& Tipping PG. Decreased plasma tissue factor pathway inhibitor in women taking combined oral contraceptives. American Journal of Hematology 199960 175-180.
34 Yamamoto C, Kaji T, Sakamoto M, Kozuka H \& Koizumi F. Calcium regulation of tissue plasminogen activator and plasminogen activator inhibitor-1 release from cultured human vascular endothelial cells. Thrombosis Research 1994 74 163-168.

35 Muller B, Tsakiris DA, Roth CB, Guglielmetti M, Staub JJ \& Marbet GA. Haemostatic profile in hypothyroidism as potential risk factor for vascular or thrombotic disease. European Journal of Clinical Investigation 200131 131-137.

36 Thompson SG, Kienast J, Pyke SD, Haverkate F \& van de Loo JC. Hemostatic factors and the risk of myocardial infarction or sudden death in patients with angina pectoris. European Concerted Action on Thrombosis and Disabilities Angina Pectoris Study Group. New England Journal of Medicine 1995332 635-641.

37 Gelehrter TD \& Sznycer-Laszuk R. Thrombin induction of plasminogen activator-inhibitor in cultured human endothelial cells. Journal of Clinical Investigation 198677 165-169.

38 Moss AJ, Goldstein RE, Marder VJ, Sparks CE, Oakes D, Greenberg H, Weiss HJ, Zareba W, Brown MW, Liang CS Lichstein E, Little WC, Gillespie JA, Van Voorhees L, Krone RJ, Bodenheimer MM, Hochman J, Dwyer EM Jr, Arora R, Marcus FI, Watelet LF \& Case RB. Thrombogenic factors and recurrent coronary events. Circulation $1999992517-2522$.

39 Feinbloom D \& Bauer KA. Assessment of hemostatic risk factors in predicting arterial thrombotic events. Arteriosclerosis, Thrombosis, and Vascular Biology 200525 2043-2053.

40 Kannel WB. Overview of hemostatic factors involved in atherosclerotic cardiovascular disease. Lipids $2005401215-1220$.

41 Scarabin PY, Aillaud MF, Amouyel P, Evans A, Luc G, Ferrières J, Arveiler D \& Juhan-Vague I. Associations of fibrinogen, factor VII and PAI-1 with baseline findings among 10500 male participants in a prospective study of myocardial infarction-the PRIME study. Prospective epidemiological study of myocardial infarction. Thrombosis and Haemostasis $1998 \mathbf{8 0} 749-756$.

42 Maroney SA \& Mast AE. Expression of tissue factor pathway inhibitor by endothelial cells and platelets. Transfusion and Apheresis Science 200838 9-14.

43 Lwaleed BA \& Bass PS. Tissue factor pathway inhibitor: structure, biology and involvement in disease. Journal of Pathology $2006 \mathbf{2 0 8}$ 327-339

44 Hoke M, Kyrle PA, Minar E, Bialonzcyk C, Hirschl M, Schneider B, Kollars M, Weltermann A \& Eichinger S. Tissue factor pathway inhibitor and the risk of recurrent venous thromboembolism Thrombosis and Haemostasis 200594 787-790.

45 Monasterio J, Bermúdez P, Quiroga D, Francisco E, Meneses B \& Montaner J. Plasma thrombin-activatable fibrinolytic inhibitor (TAFI) among healthy subjects and patients with vascular diseases: a validation study. Pathophysiology of Haemostasis and Thrombosis $200333382-386$.

46 Bajzar L, Manuel R \& Nesheim ME. Purification and characterization of TAFI, a thrombin-activable fibrinolysis inhibitor Journal of Biological Chemistry 1995270 14477-14484.

47 Juhan-Vague I, Morange PE, Aubert H, Henry M, Aillaud MF, Alessi MC, Samnegård A, Hawe E, Yudkin J, Margaglione M, Di Minno G, Hamsten A \& Humphries SE, HIFMECH study group. Plasma thrombin-activatable fibrinolysis inhibitor antigen concentration and genotype in relation to myocardial infarction in the north and south of Europe. Arteriosclerosis, Thrombosis, and Vascular Biology 200222 867-873.

Received 18 February 2009

Accepted 19 February 2009 